\title{
Influence of Employee Rewards on Transfer of Skills from Training to the Workplace in Kenyan State Corporations
}

\author{
Vincent Bosire Ochoi, Ronald Chepkilot, Charles Zakayo
}

\begin{abstract}
The study sought to assess the influence of employee rewards on transfer of skills from training to work in Kenyan state corporations. It was informed by the observation that a lot of resources are used to train public servants but the quality of services offered to the citizens has not significantly improved. The study adopted a descriptive study design. The target population for this study were all the employees of the 202 State Corporations in Kenya. The state corporations are categorized into 8 groups based on their different functions.From the 202 state corporations, the researcher sampled20 state corporations which forms $10 \%$.The researcher further adopted stratified random sampling to get the sample size of State Corporation in each category. The 20 sampled state corporations had a total population of 40467 . The sample size was determined using Slovins' formula to get 396 respondents for the study. Proportionate stratified sampling was used to get the sample size from each of the sampled state corporations. Data was collected by use of a structured questionnaire. The questionnaire was pilot tested on 38 respondents drawn from 2 state corporations. Data was analyzed using SPSS Version 24 to generate descriptive and inferential statistics and finally, data was presented with the help of frequency tables. Correlation analysis was used to test the direction of relationship between the independent and dependent variables. Regression analysis was used to test whether the independent variable have any influence on the dependent variable. The findings revealed that employee rewards have a significant influence on transfer of skills from training to work in Kenyan State Corporation. The study recommended that Kenyan state corporations come up with better reward systems to recognize the efforts put by employees who transfer training.
\end{abstract}

Index Terms - Transfer of skills, Employee rewards, State Corporation.

\section{INTRODUCTION}

Employee training is an important in improving the performance of employees. According to April (2010),training plays a vital role in the organizational development, improving performance, increasing productivity, and eventually puts organizations in the best position to face competition and stay at the top. Organizations and governments all over the world spend billions of money and a lot of other resources in training their employees, According to the Kenyan Government Recruitment policy, $2 \%$ of the government's budget is allocated to training public servants (GoK 2015). The skills and performance of employees in the work place are critical to the success of

Vincent Bosire Ochoi, Kabarak University, Kenya

Ronald Chepkilot, Kabarak University, Kenya

Charles Zakayo, Kabarak University, Kenya every organization. It is not enough to train employees, a follow up of the training is necessary to ascertain whether the skills learned have been transferred to the workplace.

Transfer of training is defined as the application of what is learned in training back on the job" (Werner \& DeSimone, 2012). According to Bulut and Culha (2010), the success and effective functioning of organizations depends not only on the training but also on training transfer to the workplace in order to achieve the organizational objectives (Bulut \& Culha, 2010). According to Edwards, training transfer is of one of the most important factors in relation to the performance of not only the employee but also of the organization (Edwards 2013). The ultimate aim of any training programme therefore, is the application of knowledge, skills and attitudes in the workplace. This success in application of skills learned is referred to as transfer of training.

Since many training reports indicate success at the training level, researchers on training effectiveness have gone beyond the classroom to explore factors within the work environment that could affect the application of skills learned in training. Employee rewards has been identified by previous researchers as some of one of the factors within the work environment that could affect transfer of training. According to Armstrong (2016), a reward is recognition of the contribution of people towards an organization by financial and nonfinancial means. It is necessary to explore the kind of effect that rewards have on employee's transfer of skills from training to the workplace.

Training of Kenyan public servants including employees of state corporations is governed by policies released by the government from time to time. The Strategy for economic recovery strategy (ERS) for example, emphasizes the developing a clear recruitment and training policy aimed at ensuring proper supply and development of skills in the civil service. It pegs promotion on both performance and training (GOK, 2003). According to the current Human resource development policy in the Kenyan Public service, from the year 2000, there was aparadigm shift in government training policy that emphasized on short term job-related courses for performance improvement and leadership development as opposed to long-term training programmes that focused on promotion (GOK, 2015). The policy states that every public servant must undergo a compulsory five days training each financial year (GOK, 2015).

\section{A. Statement of the Problem}

Organizations all over the world spend a lot of money on training their employees with the hope that the skills learned 
will be transferred to the workplace in order to improve the quality of services offered. Scholars have however established that learning in training does not automatically result in transfer of skills to the work place (Bjerregaard, Haslam, \& Morton, 2016). Research shows that indeed, many training programmes fail to deliver the expected results, that is, only a small part percentage (around 15-20\%) of training is transferred( Leimbach, 2010). Return on many training investments is low and investments in training are too often wasted due to poor transfer. This is of particular concern in today's rapidly changing business climate where organizational success often depends on the speed with which people can learn and apply new ideas and information (Wenzel \& Cordery, 2014).

The government of Kenya commits a lot of money to train public servants. State corporations in Kenya, just like other public sector organizations, usually dedicate at least $2 \%$ of their total expenditure to training with the aim of improving service delivery (GOK 2015).For example, according to the controller of budget report of 2017, a total of Kshs 3.6996 billion was spent in training Kenyan public servants during the financial 2016/2017 (GOK, 2017). Although a lot of resources have been pumped into the trainings; the quality of services offered to the citizens has not significantly improved. State corporations have faced a number of challenges including poor service delivery, insolvency and delays in project implementation (Gatamah, 2005).A series of studies across the world have been done to establish the link between employee rewards and transfer of skills from training to the work place however, most of the studies have been conducted outside Kenya. Very little if any research in the area of training transfer have focused on state Corporations in Kenya. Therefore the researcher sought to fill this gap.

H02 : Employee rewards have no significant influence on transfer of skills from training to the workplace in Kenyan State Corporations.

\section{LITERATURE REVIEW}

\section{A. Theoretical Review}

This study was guided by Expectancy theory. The expectancy theory was proposed by Vroom (1964) in an attempt to explain the psychological processes that cause motivation. He defined expectancy as a momentary belief concerning the likelihood that a particular act will precede a particular outcome. According to the theory, employees have personal goals which they like to achieve and for this reason they work in organizations. These personal goals can be fulfilled by organizational rewards or work outcomes. Therefore, the relationship between organizational rewards or work outcomes and personal goals is important i.e. to what extent organizational rewards fulfill an employee's personal goals and how attractive are those rewards to the employee.

The theory further posits that work outcomes are dependent on the individual performance of the employee. The level of belief that the individual employee has that his/her performance will result in achievement of organizational rewards/work outcomes is also important. It further clarifies that the perception of the chances by the individual employee that personal effort on his/her will lead to high performance is also important .The expectancy theory can be explained by the relationship of three main variables; expectancy, instrumentality and valence:

The expectancy theory advocates that certain behavior is reinforced based on desirable outcomes or rewards. The theory can be used to predict the behavior of employees who have completed training. The perception of the chances by the individual employee that transferring skills to the workplace and the effort exerted will lead to high performance is important. The implication for training transfer is that training would occur if there are rewards. Expectancy theory makes no attempt to define specific types of needs of rewards, but tries to establish that these needs exist and may be different for every individual. It therefore measures the strength of the individual's motivation to behave in a particular way.

The expectancy theory recognizes the importance of various individual needs and motivations. Another important aspect of this theory is that it understands the subjective differences that cause differences in motivation of different individuals

\section{B. Transfer of Training}

Transfer of training has been referred to as the application of skills gained from training back in the workplace. (Brown, McCracken, \& Hillier, 2013). It includes the maintenance of the skills learned and the behavior change over time (Ford et al, 2018). Peters et al. (2014), refer to it as the effective application by program participants of what they learned as a result of attending an education or training program. Yelon (2018), explains transfer of training as a continuous sequence of thought and action leading to application at work of what was learned in instruction. Transfer of the training is the ultimate aim of training and is often reflected in trainees' change in behavior, attitude and work performance. Without application of the new knowledge and skills acquired, the effort of training is worthless (Powell, 2011). Once a training programme is completed, trainees have to contemplate how they will apply the skills learned.

Several scholars have attempted to look at what constitutes application. According to Ford et al (2018), application involves more than mimicking responses to situations presented in training. Application focuses on the extent to which trainees exhibit new behaviors on the job in response to settings, people, and situations that differ from those presented during training. Thus, the principles and skills learned in training must then be applied by trainees in the appropriate way in a diverse set of settings and people. According to Yelon (2018), while most trainees apply new ideas to their duties just as they were taught to do, others vary their applications based on their individuality, independence, and job conditions. They modify their actions to fit their specific circumstances while trying not to subvert the effectiveness of the application.

\section{Employee Reward}

A reward is a "token of favor upon somebody." It is an equivalent for anything given or done and it simply means compensation. People will therefore contribute more and 
cooperate more wholeheartedly if they feel that they are valued (Armstrong, 2008). This happens when they are recognized for what they achieve and are rewarded according to their contribution. The type of reward practices used by an organization plays an important role in motivating employees to perform (Beer and Walton, 2014).This ultimately affects the performance of the organization (Hansen et al 2012).Based on decades of research on operant conditioning and behavior modification, it is commonly believed that if rewards are used effectively, they can motivate individuals to perform at higher levels, and the use of proper rewards culminates in firm performance at the organizational level (Giancola, 2011).

Several researchers have looked at the nature of rewards that can be used for transfer of training. Extrinsic rewards are usually financial or tangible rewards which include pay, promotion, interpersonal rewards, bonuses and benefits. According to Zaman (2011) the hygiene-motivator distinction clearly maps onto the reward-recognition distinction. In fact, Herzberg himself made this point: In his motivation-hygiene theory, Herzberg stated that work motivation is largely influenced by the extent to which a job is intrinsically challenging and provides opportunities for recognition and reinforcement. (Giancola, 2011). In other words, reward represents the application of hygiene factors, and recognition represents the application of motivator factors (Allen \& Helms, 2011).

According to Agwu. (2013) reward practices play a vital role in improving employee performance and to achieve organizational goals. He reiterates that an extrinsic rewards actually fulfills an employee's extrinsic factors or hygiene factors and thus do not let him start thinking about leaving the company. Examples include; pay rise, bonuses, paid leaves, annual recreational plans etc. Awais and Sharan (2010) Pointed out that if the trainees are intrinsically motivated, they retain and transfer the learned skills at their workplace .Their study established that trainees motivated through extrinsic rewards performed well but made more mistakes while performing their job tasks. In contrast, trainees who were motivated through intrinsic rewards performed their job tasks more accurately. Osman et al (2005) highlighted that intrinsic rewards can bring more innovation and effectiveness to an employee's performance.

Studies on the influence employee rewards on transfer of training have yielded conflicting results. The some studies indicate that indeed employee rewards have an influence on transfer of training. Khalid,et al ( 2011) conducted a study in Malasyia with the aim of examining the impacts of rewards and motivation on job satisfaction between public and private water utility organization in Malaysia. A total of 689 employees from both sectors participated in this study. The findings indicated that rewards had a positive significant influenced on motivation and that motivation significantly positively influenced employees' job satisfaction. Bhati et al. (2014) investigated the relationship between intrinsic rewards and training retention $\mathrm{He}$ collected data from employees working in the Malaysian banking sector. The study established that when trainees perceive training activities as a source of receiving intrinsic rewards, they retain more skills and transfer of learning occurs. The results of the study also indicated that intrinsic rewards influence training transfer mediated by training retention and training application.

Mansor, (2012) studied the effect of rewards towards job performance among employees in Chemical-based industries in Malaysia. The objective of the study was to determine the relationships between intrinsic rewards towards job performance and to examine the relationships between extrinsic rewards and job performance among employees in chemical-based industries. Using a quantitative approach the study established that that both the intrinsic and extrinsic rewards had an effect on performance, however, the most influential rewards booster for higher job performance of the employees in chemical-based industries was intrinsic rewards.

Muneer et al. (2017), conducted a study in the city of Faisalabad, Pakistan to measure the effect of rewards (Intrinsic \& Extrinsic) on employee job performance. The objective of the study was to establish the effect of rewards on performance of employees of different courier companies.as well as to examine the most significant types of rewards that may boost workers performance. The study established that rewards plays a motivational role in the personality of an employee and urge them to produce loyalty and show good performance. The study also revealed that there was a strong relationship between the type of rewards and employee performance.Other researchers who have indicated that employee rewards have no significant effect on transfer of training. For example, a study done by Goverts (2017) sought to establish if supervisors use rewards as means of enhancing training transfer. A good number of supervisors indicated that they did not offer rewards to induce transfer of training and in fact reiterated that they considered giving an employee an opportunity to go for training as a reward in itself.

Ahmed et al (2015), investigated whether rewards act as influencing components for transfer of training. They collected data from 117 participants with different managerial positions from the various organizations coming to attend the training programs at National Institute of Labor Administration and Training (NILAT) Karachi, Pakistan. There. The study established that there was no significant relationship between reward and transfer of training. Maina (2013) studied the influence of work environment factors influencing the transfer of learning from the Open Flexible Distance Learning Diploma in Education Management program to the work place. The respondents were 213 school principals from eight sub counties in the County Government of Kiambu, Kenya who had attended training at the Kenya Educational Management Institute (KEMI). The study revealed that schools and the Ministry of Education Science and Technology did not offer rewards or recognize those who applied skills and competencies learnt at work. Benefits such as salary increase and recognition were also not sufficiently provided when the Diploma graduates applied learning to the workplace.

Some studies have concentrated on the type of reward system and how it affects productivity .A good reward systems lead to increases labour productivity, because it acts as a motivator. Rewards may encourage workers who have 
attended training to apply skills learned. This is because they may feel that they are being valued by their employers. This also encourages them to work harder employees also look at what training will add in terms of career and self-development .Nikandrou et al. (2009) argued that trainees think that internal rewards (intrinsic rewards) are important because they help trainees develop more self-confidence and personal improvement.

Positive reinforcement for workers often takes the form of tangible rewards as well as recognition and praise. A combination of recognition and rewards, along with informal praise, is likely to be the most motivational (Kinicki and Kreitner, 2016). In his popular book 1001 Ways to Reward Employees, Bob Nelson as cited by Giancola (2011), concluded that rewards must have a positive impact on performance, and he found that the most desired form of reward by employees was verbal appreciation or praise by their immediate boss.

Many organizations have formal recognition and reward programs and these recognition programs usually include rewards because good performers are recognized with rewards (Deci, 2013). Among the rewards given are plaques, gift cards, jewelry and on the spot cast awards (Allen and Helms, 2011). More sophisticated recognition programs recognize behavior that supports organizational values, so the awards are a reminder of what is important to the company (Aguinis, 2012). According to Steers and Porter, (2011). Organizations should think critically about the compensation bundles that they offer to their workers. Monetary motivations improve the business relationship since it makes the reason for elevated amounts of duty and in this manner, firms must create systems that incorporate money related impetuses and rewards for instance advancement, reward, benefit sharing or addition sharing and workers stock proprietorship and so forth (Ismail, et al , 2009).

Many jobs require financial rewards to motivate employees and many people primarily work to make money or attain the recognition denoted by financial rewards (Giancola, 2011). According to Kinicki and Kreitner (2016), financial incentives are more effective when they are linked to (or contingent upon) good performance. A key principle is for managers to explain clearly to employees how performance is linked to pay, including the fact that unethical behavior will not be tolerated as a way of attaining a performance goal (Steers and Porter, 2011). An increasing effort of managers and compensation specialists to link pay to performance supports many business strategies. Workers receive financial incentives for performing in ways consistent with the business strategy (Aguinis, 2012).

Literature has shown that remuneration issues play a critical role in organizations; however, there has been little advice that companies could use in terms of when certain incentive system designs have been more or less appropriate (Dubrin, 2012). The type of reward and incentives utilized by an organizations is important in spurring workers to perform (Beer and Walton, 2014). This ultimately affects the performance of the organization. (Hansen, Smith and Hansen, 2012), it is commonly believed that if rewards are used effectively, they can motivate individuals to perform at higher levels, and the use of proper rewards culminates in firm performance at the organizational level (Giancola, 2011). He observed that rewards must have a positive impact on performance, and he found that the most desired form of reward by employees was verbal appreciation or praise by their immediate boss.

Many organizations have formal recognition and reward programs and these recognition programs usually include rewards because good performers are recognized with rewards (Deci, 2013). Among the rewards given are plaques, gift cards, jewelry and on the spot cast awards (Allen \& Helms, 2011). More sophisticated recognition programs recognize behavior that supports organizational values, so the awards are a reminder of what is important to the company (Aguinis, 2012).

Teams, as well as individuals should receive recognition to enhance motivation (Riggio, 2014). As with most motivation and retention programs, recognition and rewards must be carefully planned, otherwise they may backfire and lose money for the company (Kinicki \& Kreitner, 2016). Increasingly, it has become clear that the battle for talent involves much more than highly effective, strategically designed compensation and benefit programs. While these programs remain critical, the most successful companies have realized that they must make a much broader look at the factors involved in attraction, retention, and motivation (Giancola, 2011) And they must deploy all of the factors, including compensation and benefits, to their strategic advantage (Hansen, Smith and Hansen, 2012). Praising workers for good performance is a major type of informal recognition (Allen and Helms, 2011).

Although praise costs no money and only requires a few moments of time, many workers feel that they do not receive enough praise (Aguinis, 2012) managers therefore have a good opportunity to increase motivation by the simple act of praising good deeds (Kinicki \& Kreitner, 2016). Rewards reflect both personal and institutional goals, and stand to assist an understanding of what directs both individuals' engagement and workplace affordances (Allen and Helms, 2011). In this way, rewards capture the goals for both workplace and personal trajectories, and permit a consideration of the degree to which there is consonance between these trajectories (Judge and Ferris, 2013). Hence they richly inform the relational interdependence 20 between the personal and social. In general, there seems to be agreement that recognition and rewards are important motivators for individual and for organizational performance (Hansen, Smith \& Hansen, 2012). 


\section{Conceptual Framework}

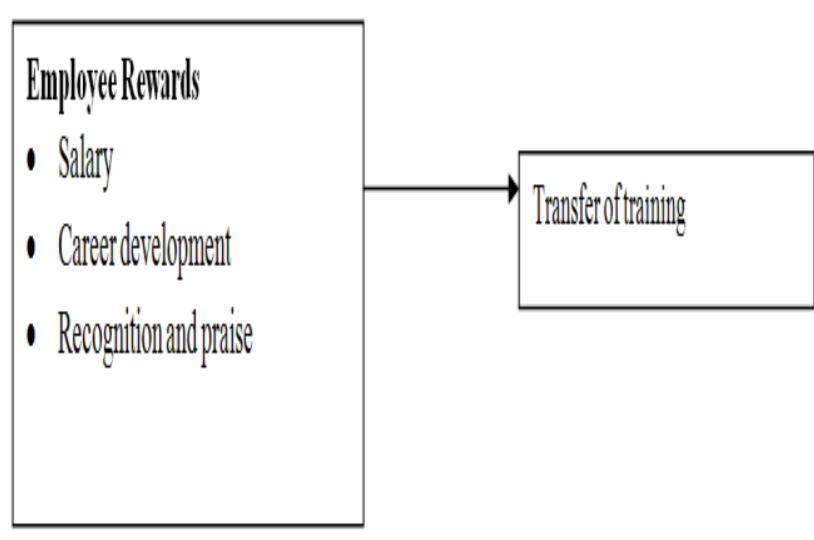

Figure 1: Conceptual Framework

\section{METHODOLOGY}

\section{A. Research Philosophy}

The research adapted pragmatism paradigm in examining issues raised in this research. For many, pragmatism as a worldview arises out of actions, situations, and consequences rather than antecedent conditions (as in post positivism).

\section{B. Research Design}

The research adopted a descriptive survey design. A descriptive survey design collects information from a sample drawn from a predetermined population using a predetermined set of questions. Descriptive design has an advantage in that it draws a sample of the population and then generalizes the finding from the sample to the population (Graziano \& Raulin, 2007).

\section{Population of Study}

The target population was all theemployees working in 202 State corporations in Kenya as per the Inventory of state Corporations obtained from the State Corporations Advisory Committee (SCAC 2018).

\section{Sampling Design}

From the 202 state corporation, the researcher selected 20 state corporations which forms $10 \%$ of the list of 202 state corporations. This sufficiently met the minimum threshold sample size suggested by (Gay, 1996) that a sample size of $10 \%$ of the target population is regarded as adequate for small population $(\mathrm{N}<1000)$. The researcher further adopted stratified random sampling to get the sample size of State Corporation in each category. The 20 sampled state corporations had a total population of 40467. The researcher further used Slovins' formula to get a sample size of 396 respondents

\section{E. Data Collection Instruments}

The researcher use closed ended questionnaires based on Likert scale as the main mode of data collection. The use of questionnaires is justified because they assured an effective way of collecting information from a population in a short period of time and at a reduced cost. The questionnaires also facilitate easier coding and analysis of data collected (Kothari, 2004). The closed ended questions ensured that the respondents are guided to the relevant area of concern of the study.

Validity was addressed through honesty in reporting, interpreting the depth of experiences, the richness and scope of the data achieved, the participant approached and the disinterestedness of objectivity of the researcher (Cohen, Manion \&Morrison, 2007). The researcher sought the assistance of experts in the field of human resource management in Kabarak University and guidance from fellow doctorial students. Their comments were incorporated so as to improve the validity of the instrument. To determine the reliability of the instruments (questionnaire), the researcher adopted the test retest technique, where the questionnaire was administered twice to the respondents in the pilot sample. A total of 38 questionnaires were administered to employees of 2 state corporations and this formed the data used in the pilot study.

\section{G: Data Analysis}

Data was analyzed with the aid of the Statistical Package for Social Sciences (SPSS) version 24. The analysis enabled the researcher to determine the nature and extent of the relationship between the variables.Descriptive statistics and inferential statistics were used in this research. Multiple regression was used to test the hypotheses. The relationship between the dependents and independents variable was analyzed using a regression model below.

Model I: $Y=\beta 0+\beta_{1} X_{1}+\varepsilon$

$\mathrm{Y}=$ Transfer of training

$\beta 0=$ constant

$=$ parameter estimates

$\mathrm{X} 1=$ Employee Rewards

\section{RESULTS}

\section{A. Response Rate}

A total of 396 questionnaires were issued out to respondents from the sampled state corporations. Completed questionnaires that were received were 369 which represented 93\% response rate. According to Fincham (2008), a response rate of above $60 \%$ is considered appropriate in Research

\section{B. Background Information}

The study examined the background information of respondents in respect to the age and gender of the respondents. From the findings $38.5 \%(142)$ of the respondents were aged 40-49 years, $29.5 \%$ ( 109) were 50-59 years old, $24.1 \%$ ( 89) were 30-39 years old. Further, $6.5 \%$ ( 24) were between 18 and thirty 30 years old. Only $1.3 \%$ ( 5) were above 60 years. The findings also established that over half $(57.5 \%)$ of the respondents were female, whereas $42.5 \%$ were male.

\section{Length of course undertaken}

It was established that all the respondents had attended a course/training. They were asked to state the period the course took. The responses are shown in Table 1 
Table 1: Length of course undertaken

\begin{tabular}{ccc}
\hline Length of course & Frequency & Percent \\
\hline 1-5 days & 147 & 39.8 \\
6-10 days & 69 & 18.7 \\
3-4 weeks & 97 & 26.3 \\
5-6 weeks & 15 & 4.1 \\
above 6 weeks & 29 & 7.9 \\
any other & 12 & 3.3 \\
\hline Total & $\mathbf{3 6 9}$ & $\mathbf{1 0 0 . 0}$ \\
\hline
\end{tabular}

Source: Research Data 2018

The finding shows that $39.8 \%$ of the respondents attended a training that lasted for $1-5$ days whereas $26.3 \%$ attended a training that lasted for 3-4 weeks. Further, $18.7 \%$ attended a training that took over 6 weeks these were $4.1 \%$ (15) who attended a training that lasted for 5-6 weeks.

B. Findings and Discussions

Table 2: Employee Rewards

\begin{tabular}{|c|c|c|c|c|c|c|c|c|}
\hline & & & & & & & & $\mathrm{P}>$ \\
\hline & $\mathrm{NE}$ & VSE & SE & $\mathrm{ME}$ & LE & VLE & $\chi^{2}$ & $\chi^{2}$ \\
\hline $\begin{array}{l}\text { I get recognition for using the skills } \\
\text { learned in training }\end{array}$ & 15.7 & 4.3 & 16.5 & 16.3 & 30.9 & 16.3 & 78.8 & $<.0001$ \\
\hline $\begin{array}{l}\text { I get verbal praise for applying the skills } \\
\text { learned in training }\end{array}$ & 13.3 & 6.2 & 18.7 & 12.2 & 31.2 & 18.4 & 79.2 & $<.0001$ \\
\hline $\begin{array}{l}\text { I was promoted for applying the skills } \\
\text { learned in training }\end{array}$ & 26.6 & 6.8 & 12.5 & 11.4 & 28.7 & 14.1 & 87.1 & $<.0001$ \\
\hline $\begin{array}{l}\text { I was given some days off for applying } \\
\text { the skills learned in training }\end{array}$ & 41.5 & 5.2 & 7.9 & 13.8 & 17.6 & 14.1 & 186.1 & $<.0001$ \\
\hline $\begin{array}{l}\text { I was given salary increment for applying } \\
\text { skills learned in training }\end{array}$ & 40.1 & 7.3 & 12.7 & 13.0 & 19.5 & 7.3 & 168.5 & $<.0001$ \\
\hline $\begin{array}{l}\text { I was given bonus for applying the skills } \\
\text { learned in training }\end{array}$ & 43.7 & 8.2 & 15.0 & 10.9 & 13.4 & 8.7 & 200.4 & $<.0001$ \\
\hline $\begin{array}{l}\text { I was given another training as an } \\
\text { appreciation for applying the skills } \\
\text { learned in training }\end{array}$ & 43.4 & 14.9 & 8.9 & 13.0 & 9.2 & 10.6 & 195.1 & $<.0001$ \\
\hline $\begin{array}{l}\text { I was given tangible gifts as a result of } \\
\text { applying skills learned in training }\end{array}$ & 45.3 & 14.6 & 12.2 & 10.8 & 6.0 & 11.1 & 226.0 & $<.0001$ \\
\hline $\begin{array}{l}\text { I was given a holiday trip as a result of } \\
\text { applying the skills learned in training }\end{array}$ & 49.1 & 9.2 & 17.1 & 8.1 & 5.4 & 11.1 & 295.5 & $<.0001$ \\
\hline
\end{tabular}

Source: Research Data 2018

The findings in table 2 reveal that $\left(47.2 \%, x^{2}=78.8\right.$, $\mathrm{P}<.0001)$ of the respondents who participated in this study stated that to large extent they get recognition for using the skills acquired in training while $16.3 \%, x^{2}=79.2, \mathrm{P}<.0001$ ) of the respondents stated that to large extent they got verbal praise for applying the skills acquired in training while $12.2 \%$ indicated to a moderate extent. Recognizing employees as leading specific categories, such as sales, customer service, or support, will make them feel validated. The managers ought to try putting a leaderboard up in the break room to showcase their monthly winners. The best employees are the rock stars of the company. Providing them with the opportunity to lead by example will reinforce the idea that their accomplishments are, in fact, exemplary. Recognition has a timing element: it must occur so that the performance recognized is still fresh in the mind. If high performance continues, recognition should be frequent but cautiously timed so that it doesn't become automatic. Furthermore, like rewards, the method of recognition needs to be appropriate for the achievement. This also ensures that those actions which go farthest in supporting corporate goals receive the most attention. However, an entrepreneur should remain flexible in the methods of recognition, as different employees are motivated by different forms of recognition.

In addition $42.8 \%,\left(x^{2}=87.1, \mathrm{P}<.0001\right)$ of the respondents stated to a large extent, they were promoted for applying skills acquired in training while $11.4 \%$ to a moderate extent and $19.3 \%$ to a small extent less than half $31.7 \%$,( $\left.x^{2}=186.1, \mathrm{P}<.0001\right)$. As a sign of the value and esteem that an employee is held in by the employer, the promotion is a visible action that other employees see. In all cases of promotion, the employer is telegraphing to other employees the kinds of actions, behaviors, and values he'd like to see in their attitudes, outlooks, contributions, and commitment. Sometimes a promotion results in an employee taking on responsibility for managing or overseeing the work of other employees. Decision-making 
authority tends to rise with promotion as well.

In addition the respondents stated that to large extent they were given some days off for applying skills learnt in training whereas $13.8 \%$ to a small extent. The study concurs with Stapleton(2017) who noted that time off schemes are not yet widespread in the workplace, but some companies are experimenting with offering time back as a reward for hitting targets. It doesn't necessarily replace conventional bonus or commission packages, but it offers a new way to incentivize staff, in line with the broader trend towards flexible working. The benefit of offering time off as a bonus or reward is that it's essentially free for the company to do this. You could say that there is the cost of lost productivity and there may even be the cost of replacement in some cases but the payroll cost of offering time off should be low to nothing. Offering time off is a creative way to get employees to follow difficult rules. For example, in an environment where employees need to be at work on time, some fraction of an hour of time off can be offered when employees get to work on time.

It was also noted that majority $40.1 \%\left(x^{2}=186.5, \mathrm{P}<.0001\right)$ were never given salary improvement for applying skills acquired in training. Employees who perform better by employing their skills after training may be rewarded by increasing their salaries. Employees are advancement of an employee from one job position to another job position that has a higher salary range, a higher level job title, and, often, more and higher-level job responsibilities in an organization. Financial reward is a common way of recognizing a job well done. This is usually seen in the form of a wage or salary increase but not always. Wage and salary rises can be an effective motivational tool yet it is recommended that they are kept in line with the farm business objectives and financial limitations. Employees receive a salary or wage for performing the functions of their position. The specific salary amount paid is dependent on many factors such as: market rates,

Table 3: Correlation between employee reward and transfer of skills from training to work. qualifications of the employee, their experience, their competence and aptitude, and their potential for advancement. (Ferry Hay Group's, 2016).

The study also revealed that most of the respondents 44.2 $\%\left(x^{2}=200.4, \mathrm{P}<.0001\right) \quad$ were not given bonuses for applying skills acquired in training. Only $22 \%$ (88) to small extent and $13 \%$ (48) to moderate extent. Giving bonuses is good for employee retention and for productivity. When employees know a bonus is coming, they are motivated to accomplish more. When employees receive them unexpectedly, it is a clear signal that they're doing good work. Bonuses make employees happy, which usually benefits the company overall.

Similarly, $45.3 \%\left(x^{2}=226.0, \mathrm{P}<.0001\right)$ of the employees who participated in this study stated that they are never given tangible gift as a result of applying skills acquired in training while $10.8 \%$ to a moderate extent. . Further, $49.1 \%\left(x^{2}=295.5, \mathrm{P}<.0001\right)$ of the respondents stated that they were never given a holiday trip as a result of applying skills acquired in training while $8.1 \%$ to a moderate extent and $26.3 \%(97)$ to a small extent. Further, $49.1 \%$ of the respondents stated that they were the respondents stated that they were never given a holiday trip as a result of applying skills acquired in training while $8.1 \%$ to a moderate extent and $26.3 \%$ to small extent. The findings indicate that most of the respondents were not given tangible rewards, however non- tangible rewards e.g. recognition were given. The study agrees with Goverts (2017) who sought to establish if supervisors use rewards as means of enhancing training transfer. A good number of supervisors indicated that they did not offer rewards. In the study, some supervisors reiterated that even an opportunity to go for training was a reward in itself. Correlation Analysis.
Pearson Correlation

Sig. (2-tailed)

$\mathrm{N}$
$.210 * *$

.012

369

\footnotetext{
*. Correlation is significant at the 0.01 level (2-tailed).

The study further sought to establish the nature of the relationship between employee rewards and transfer of skills from training to work in Kenyan State Corporations. The findings indicated that $r=0.210$ and $p=0.012$. The $p$ value was less than the significant level of 0.01 meaning that there is positive statistically significant relationship between employee rewards and transfer of skills from training to work in Kenyan State Corporations. This
}

implies that employee rewards has a significant statistical influence on transfer of skills from training to work in Kenyan State Corporations. According to and Kontoghiorghes (2004) employees may perform better if they believe learning transfer will lead to rewards. In his study of 'factors that motivate business faculty to conduct research. 
Table 4: Regression Coefficients ${ }^{\mathrm{a}}$

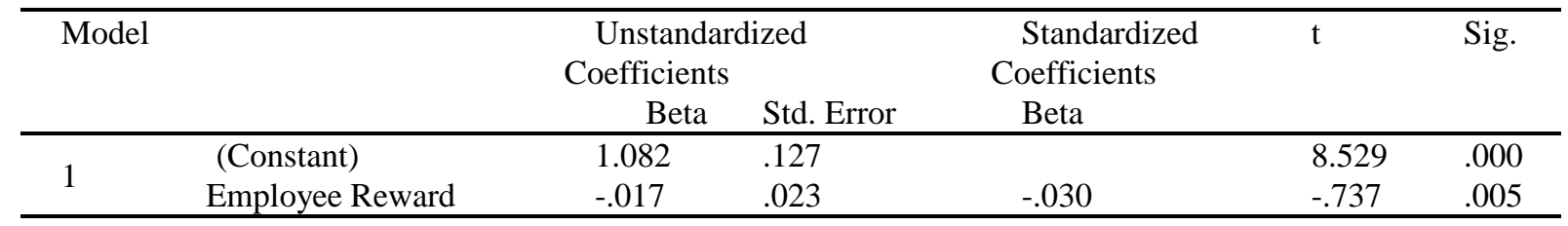

a. Dependent Variable: Transfer of skills from training to work. The value of transfer of skills from training to work in Kenyan Sate Corporations without the influence of the predictor variables is 1.195 . This explains that, at any given time transfer of skills from training to work in Kenyan Sate Corporations will be 1.195 holding other factors constant at 0 . The results also illustrate that, a unit change in peer support would result to -0.047 times increase in transfer of skills from training to work in Kenyan State Corporations.

\section{$\mathrm{Y}=1.082-0.017+\varepsilon$}

The study sought to test the hypothesis that: H01: Employee Reward has no significant influence on transfer of skills from training to work in Kenyan State Corporations. From the findings the $\mathrm{p}$-value was less the 0.01 significant level. Therefore, based on the rule of significance, the study rejects the null hypothesis (H01) and concluded that peer support have a significant influence on transfer of skills from training to the work place in Kenyan Sate Corporations. The study agrees with Bhati (2014) who found out that when trainees perceive training activities as a source of receiving intrinsic rewards, they retain more skills and transfer of learning occurs

\section{CONCLUSION \& RECOMMENDATION}

\section{A. Conclusion}

The study concludes that that most of the respondents were not given tangible rewards, however non- tangible rewards e.g. recognition were given. The study agrees with Goverts (2017) who sought to establish if supervisors use rewards as means of enhancing training transfer. A good number of supervisors indicated that they did not offer rewards. The study also concluded that employees rarely get recognition, promotion, salary improvement, bonuses and tangible gifts as a result of applying skills acquired in training. Majority of the employees were never given a holiday trip as a result of applying skills acquired in training.

B. Recommendations

The type of reward offered has an effect on the valence of the rewards hence it is recommended that Kenyan state corporations come up with better reward systems to recognize the efforts put by employees who transfer training.

\section{REFERENCES}

[1] Aguinis, H. (2012). Performance Management (Second ed.). Upper Saddle River, NJ: Prentice Hall

[2] Agwu, M. (2013). Impact of fair reward system on employees ${ }^{e e}$ job performance in Nigerian Agip Oil Company Limited, Port Harcourt. British Journal of Education, Society and Behavioral Science, 3(1) 47-64.

[3] Allen, R. \& Helms, M. (2011). Reward Practices and Organizational Performance.Compensation Benefits Review, Vol 33, Issue 4, pg. 74-80.

[4] April, C. (2010). Employee turnover: implications for hotel managers. FIU Hospital Review, 3(8): 24-31.

[5] Armstrong, M. (2009). Armstrong's Handbook of Human Resource Management Practice, 11th edn, London: Kogan Page

[6] Beer, M. \& Walton, R. E. (2014). Reward Systems and the Role of Compensation. In J. G. Searle, Manage people, not personal (p. 17). Boston: Harvard Business Review.

[7] Bhatti, A., Ali, S., Isa, M. \& Battour, M. (2014). Training Transfer and Transfer Motivation: The Influence of Individual, Environmental, Situational, Training Design, and Affective Reaction Factors. Performance Improvement Quarterly, 27 (1): 51-82.

[8] Cohen, L., Manion, L., \& Marrison, K. (2007). Research Methods in Education. British : Taylor and Francis e-Library .

[9] Deci, E. (2013). Intrinsic Motivation. New York, NY: Plennum Press.

[10] Dubrin, A. (2012). Essentials of Management. Mason, OH: Cengage South-Western.

[11] Edwards, S. J. (2013). Factors affecting training transfer in supervisor and hourly employees in manufacturing organization. Southern Cross University

[12] Ford, K., Yelon, L., \& Billington, Q. (2011). How much is transferred from training to the job? The $10 \%$ delusion as a catalyst for thinking about transfer. Performance Improvement Quarterly, 24(2), 7-24. https://doi.org/10.1002/piq.20108

[13] Giancola, F. (2011). Examining the job itself as a source of Employee Motivation. Compensation and Benefits Review, Vol. 43, Issue 1, pg. 23-29.

[14] GOK. (2012). Sessional paper no 10 of 2012 on vision 2030 . Nairobi : Government Printer

[15] GoK. (2015). Human resource development policy for public service . Nairobi : Government Printer

[16] Govaerts, N. \& Dochy, F. (2014). Disentangling the role of the supervisor in transfer of training. Educational Research Review, 12: 77-93.

[17] Govaerts N, (2017). A supervisor's perspective on their role in transfer of training.Human resource development Quarterly Volume 28, Issue 4

[18] Graziano, A.M and Raulin, M. L. (2006). Research methods: a process of inquiry, $\left(6^{\text {th }} \mathrm{Ed}\right)$ Boston, M. A: Allyn \& Bacon.

[19] Hansen, F., Smith, M. \& Hansen, R. (2012). Compensation and Benefits Review. Rewards and Recognition in Employee Motivation, Vol. 34, Issue 5, pg. 64-72.

[20] Judge, T. \& Ferris, G. (2013). Social context of performance evaluation decisions. Academy of Management Journal, Vol 36, Issue 3, Pg. 80-105.

[21] Khalid, T. (2011) The Impact of Rewards and Motivation on Job Satisfaction in Water Utility Industry 2011 International Conference on Financial Management and Economics IPEDR vol.11 (2011) @ (2011) IACSIT Press, Singapore

[22] Kinicki, A. \& Kreitner, R. (2016). Organizational Behavior: Key Concepts, Skills \& Best Practices. New York, NY: McGraw-Hill.

[23] Kothari, C. R. (2004). Research Methodology: Methods and Techniques. New Delhi: 2nd Edition, New Age International Publishers

[24] Leimbach, M. (2010). Learning transfer model: A research driven approach to enhancing learning effectively. Industrial and Commercial Training, 42(2), 81-86.

[25] Mansor, D. (2012) The Effect of Rewards towards Job Performance among Chemical-Based Employees International Journal of Business and Management Tomorrow Vol. 2 No. 12

[26] Mugenda, M. O., \& Mugenda, A. G. (2003). Research Methods, Quantitative and Qualitative Approaches. Nairobi : Act.

[27] Nikandrou, I., Brinia, V., \& Bereri, E. (2009). Trainee perceptions of training transfer: An empirical analysis. Journal of European Industrial Training, 33(3), 255-270. oi:10.1108/03090590910950604

[28] Riggio, R. (2014). Introduction to Industrial/ Organizational Psychology. Upper Saddle River, NJ: Prentice Hall.

[29] Steers, R. \& Porter, L. (2011). Motivation and work performance. New York, NY: McGraw-Hill. 